\title{
Impacto de la regulación emocional en el aula: Un estudio con profesores españoles
}

\author{
Sara SANTANDER TRIGO \\ Martha Leticia GAETA GONZÁLEZ \\ Valentín MARTíNEZ-OTERO PÉREZ
}

Datos de contacto:

Sara Santander Trigo

Universidad Complutense de Madrid

s.santander.trigo@gmail.com

Martha Leticia Gaeta González

Universidad Popular Autónoma

del Estado de Puebla

marthaleticia.gaeta@upaep.mx

Valentín Martínez-Otero Pérez Universidad Complutense de Madrid valenmop@edu.ucm.es

\section{RESUMEN}

La capacidad de regular los estados emocionales ha sido considerada como un aspecto esencial de la educación integral de las personas al posibilitar el bienestar personal, la socialización y el logro laboral y académico, entre otros beneficios. La percepción que tiene el profesorado sobre su propia regulación emocional y la del alumnado incide en su labor profesional en el aula. El objetivo del presente trabajo fue analizar el impacto de la regulación emocional en el aula, desde la perspectiva de 200 profesores de distintos niveles educativos en España. Para ello se evaluó el nivel de regulación emocional del profesorado, mediante el TMMS-24, así como el nivel de regulación emocional del alumnado percibido por el profesorado y el impacto de la regulación emocional en el proceso de enseñanza-aprendizaje, mediante instrumentos diseñados ad hoc. Los resultados muestran que, a mayor nivel de regulación emocional del profesorado, mayor importancia dada a la formación específica en regulación emocional, mayor cantidad de recursos destinados para ello y mayor motivación ante la falta de regulación emocional del alumnado, al considerarla como un reto. Estos hallazgos tienen implicaciones importantes en las pautas de actuación e intervención para la educación emocional en el aula.

PALABRAS CLAVE: Regulación emocional; Inteligencia emocional; Profesorado; Sistema educativo español. 


\title{
Impact of Emotional Regulation in the Classroom: a Study with Spanish Teachers
}

\begin{abstract}
The ability to regulate emotional states is an essential aspect of the integral education of people by enabling personal well-being, socialization, and work and academic achievement, among other benefits. The perception of teachers about their emotional regulation and that of students influences their professional work in the classroom. The objective of this paper was to analyze the impact of emotional regulation in the classroom from the perspective of 200 teachers of different educational levels in Spain. For this purpose, we evaluated the level of emotional regulation of teachers, using the TMMS-24, as well as the level of emotional regulation of students perceived by teachers and the impact of emotional regulation on the teaching-learning process, through instruments designed ad hoc. Results show that the higher the level of emotional regulation of the teaching staff, the higher the importance given to specific training in emotional regulation, the higher the number of resources used and the greater motivation, given the lack of emotional regulation of the students, considering it as a challenge. These findings have important implications in the action and intervention guidelines for emotional education in the classroom.
\end{abstract}

KEYWORDS: Emotional regulation; Emotional intelligence; Teachers; Spanish education system.

\section{Introducción}

Durante mucho tiempo la educación centró sus esfuerzos en el desarrollo cognitivo del alumnado, soslayando su desarrollo afectivo y emocional, percibido como un terreno oscuro e incluso como una influencia negativa para el desarrollo intelectual. En la actualidad, resulta innegable la importancia que presenta la dimensión afectiva para el desarrollo integral del alumnado y como recurso para potenciar el proceso de enseñanza-aprendizaje (Delors, 1996; Martínez-Otero y Velado-Guillén, 2002; Martínez-Otero, García-Domingo y VeladoGuillén, 2005).

Como bien nos recuerdan Alonso y Escorcia (2003, p. 4), el ser humano es un ser dotado de inteligencia, voluntad, afectividad, etc., es decir, de personalidad, y, por ello, es indispensable orientar desde la 
educación la formación de esa personalidad, a través de todos los ámbitos: emocionales, cognitivos y actitudinales, teniendo en cuenta el entorno y la temporalidad.

El despliegue de las emociones requiere educación inicial y permanente. A este respecto, Salovey y Mayer (1997, como se cita en Berrocal y Extremera, 2005) introdujeron hace unas décadas el constructo de inteligencia emocional (IE), que abrió un fructífero campo de investigación. Para estos autores, la IE constituye la capacidad para procesar la información que nos aportan las emociones. Las personas emocionalmente inteligentes se caracterizan por desarrollar diferentes estrategias para regular o manejar diferentes estados emocionales en la búsqueda del bienestar personal y social (Gardner, 2011; Goleman, 2014).

Por su parte, Martínez-Otero (2007) define la inteligencia afectiva como "la capacidad para conocer, expresar y gobernar la cognición y la afectividad, sobre todos los sentimientos, las emociones, las pasiones y motivaciones" (p.82). Este autor plantea, como parte del desarrollo de la inteligencia afectiva, la necesidad de control de la afectividad, realidad fundamental en el bienestar personal.

En este mismo sentido, Bisquerra (2009, p.132), concibe la IE como "una metahabilidad que determina en qué medida podremos utilizar correctamente otras habilidades que poseemos, incluida la inteligencia... es una de las habilidades de vida que deberían enseñarse en el sistema educativo...", entendiendo que, el fomento de la IE en el aula contribuye al equilibrio personal y a la felicidad de los educandos.

En España, el estado de la educación socioemocional se ha evaluado desde 2008, a través de la Fundación Botín, como vía para buscar la respuesta ante la contradicción encontrada (presentar un estado económico y de bienestar estable y positivo para los educandos, y a su vez una situación de salud mental y social, que presenta una necesidad de atención desde el sistema educativo); aspecto que aumenta el interés desde la comunidad científica de potenciar la educación del ámbito socio-emocional (Berrocal, 2008).

Asimismo, la necesidad de una educación integral se respalda desde el marco legislativo. La Ley Orgánica 8/2013, de 9 de diciembre, para la Mejora Educativa (LOMCE), señala que "Las Administraciones educativas dispondrán los medios necesarios para que todo el alumnado alcance el máximo desarrollo personal, intelectual, social y emocional" (2013, p. 97896), lo cual exige una atención a la educación emocional, con objetivos pertinentes y enfocada al desarrollo de conocimientos, aptitudes y actitudes necesarios para la adaptación del alumnado al entorno y la consecución de sus metas vitales.

De hecho, se han desarrollado distintas iniciativas educativas a 
nivel nacional, dirigidas a potenciar la IE de los distintos agentes educativos y del alumnado, entre otras: el Material de la Diputación de Guipúzcoa de Inteligencia Emocional (Berrocal, 2008); el programa Educación Responsable (Fundación Botín, 2017); el Grupo de Investigación en Orientación Psicopedagógica (GROP, s.f.); el Programa Ulises (Autismo Madrid, 2014); el Programa Construye tu Mundo (Fundación de Ayuda contra la Drogadicción, 2011); el Programa de Educación Emocional de Manuel Segura y Margarita Arcas (Miñaca, Hervás y Laprida, 2013); el Antiprograma de Educación Emocional (Román y Calleja, 2012); el Programa Aulas Felices (Rey, Valero, Paniello y Monge, 2012); el Programa Cultivando Emociones (Verdet, 2011); Decide tú (Segura y Arcas, s.f.).

Con base en los planteamientos anteriores surge el interés y la necesidad de continuar la investigación sobre el impacto de la regulación emocional en las aulas de distintos contextos y niveles escolares, entendiendo que es un factor significativo que incide sobre la calidad educativa y el bienestar social y personal de los agentes educativos implicados.

\section{La regulación emocional}

\section{La regulación emocional en el aula}

La regulación emocional ha sido concebida como una de las competencias básicas de la IE (Bisquerra, 2009). Supone la habilidad para vigilar y regular las emociones propias y ajenas, reconociendo su influencia y utilidad, a la vez que la capacidad de estar abierto a la influencia emocional negativa y positiva; un concepto bidimensional (interno y externo) y práctico (Mayer y Salovey, 1997, citados en Berrocal y Extremera, 2005).

Bisquerra (2003) define la competencia de regulación emocional como "la capacidad para manejar las emociones de forma apropiada" (p. 23) y desglosa este constructo en cinco micro-competencias: a) Tomar conciencia de la interacción entre emoción, cognición y comportamiento; b) Expresión emocional; c) Capacidad para la regulación emocional; d) Habilidades de afrontamiento; e) Competencia para autogenerar emociones positivas.

Si se añade la toma de conciencia entre la emoción, cognición y conducta, la tolerancia a la frustración y la capacidad de autogenerar emociones positivas para lograr objetivos vitales, advertimos que la regulación emocional es una capacidad flexible y que predispone al aprendizaje, así como a la vigilancia y ajuste de las emociones propias y ajenas. Como señala Martínez-Otero (2007), debe reconocerse su 
relevancia y utilidad a nivel cognitivo y conductual, en concreto su potencialidad para modular los estados emocionales ante situaciones adversas, así como para autogenerar emociones positivas impulsoras de equilibrio afectivo, en búsqueda del bienestar personal.

Diversos estudios han demostrado la incidencia de la regulación emocional en distintos ámbitos de la salud mental, sobre todo en aspectos relacionados con la depresión y la ansiedad. Además, favorece la eficacia ante situaciones de estrés (Andrés, Castañeiras y Richaud, 2014) y de consumo de drogas en edades tempranas (MartínezGonzález, Piqueras y Ramos, 2010), que reclaman también atención educativa. De ahí que desde la educación formal sea indispensable promover la regulación emocional, que permita al alumnado un desarrollo pleno y saludable (Márquez-Cervantes y Gaeta-González, 2017; Navas y Bozal, 2012).

\section{La regulación emocional en el profesorado}

El estudio de la IE en los docentes se ha incrementado en los últimos años, acaso porque son muy elevados los índices de afectaciones psicológicas (estrés, ansiedad...) en el profesorado (Martínez-Otero et al., 2005, 2006; Millán, García-Álvarez y D’Aubeterre, 2014), particularmente entre los docentes más jóvenes (Aguayo-Muela y Aguilar-Luzón, 2017), derivados de situaciones laborales negativas, así como de creencias irracionales sobre distintos aspectos de la realidad.

Con arreglo a lo dicho, debe considerarse que el estrés no solo surge como consecuencia del ambiente laboral, sino de la forma de reaccionar de la persona (Martínez-Otero et al., 2005). De ahí que la competencia socioemocional del profesorado sea un indicador clave del proceso de enseñanza-aprendizaje $\mathrm{y}$ de las relaciones interpersonales e intrapersonales en el contexto escolar (Martínez-Otero y Velado-Guillén, 2002; Palomero, 2009). Los docentes con mayor IE percibida presentan menores niveles de estrés y niveles más altos de satisfacción vital y profesional, más motivación y emociones más agradables en el proceso de enseñanza-aprendizaje (Pena, Rey y Extremera, 2012; Rey y Extremera, 2011). Sin embargo, como han encontrado distintos investigadores (Adame, Iglesia, Gotzens, Rodríguez y Sureda, 2011), las estrategias socioemocionales usadas por los docentes ante situaciones de conflicto son mayoritariamente aquellas que se relacionan con la inteligencia interpersonal, sin atender a la autorregulación emocional. Esto coincide con la necesidad de formación docente, en la que también han de considerarse las competencias emocionales intrapersonales (Cejudo, López-Delgado, Rubio y Latorre, 2015; Martínez-Otero et al., 2005, 2006). 
Se sabe que el profesorado que presenta un mayor nivel de IE muestra mayor satisfacción, ajuste y desempeño laboral (MartínezOtero et al., 2005) y recibe valoraciones más positivas por parte de sus iguales y por los agentes educativos (Echevarría y López-Zafra, 2011). Por su parte, la IE en el alumnado, y con ello la regulación emocional, presenta beneficios en su nivel de bienestar y ajuste psicológico; al tener más posibilidades de minimizar las consecuencias negativas derivadas de situaciones educativas altamente estresantes (Martinez-Otero et al., 2006), en el tipo de relaciones interpersonales y en el rendimiento académico, así como una disminución de conductas disruptivas y consumo de drogas (Extremera y Fernández-Berrocal, 2004b).

\section{Investigación realizada}

La presente investigación tiene como objetivo general analizar la incidencia de la regulación emocional en el aula, percibida por el profesorado de distintos niveles educativos en España. Se concretaron cuatro objetivos específicos:

- Identificar el nivel de regulación emocional del profesorado.

- Identificar el nivel de regulación emocional del alumnado percibido por el profesorado.

- Analizar la percepción docente respecto a la incidencia de la regulación emocional en el proceso de enseñanza-aprendizaje.

- Analizar la relación entre el nivel de regulación emocional del profesorado y la incidencia de la regulación emocional en el proceso de enseñanza-aprendizaje.

\section{Método}

\section{Participantes}

La muestra quedó constituida por 200 docentes españoles, 48\% $(n=96)$ varones y $52 \%(n=104)$ mujeres, con edades entre 21 y 63 años (media $=41,98$ años; DT=10,49). La formación docente es diversa: Máster de Formación del Profesorado de Educación Secundaria Obligatoria y Bachillerato (60\%), Magisterio de Educación Infantil (22\%), Magisterio de Educación Primaria (20\%), Magisterio de Educación Infantil y Primaria (7\%) y Magisterio de Educación Primaria y Máster de Educación Secundaria (2\%). Además, del total de la muestra, un 33\% de docentes cuenta con estudios de Postgrado. Los años de experiencia profesoral oscilan entre menos de 1 año y 40 años (media=13,39 años; $\mathrm{DT}=10,665$ ).

El profesorado ejerce en las etapas de Educación Secundaria 
Obligatoria y Bachillerato (42\%), Educación Primaria (18\%), Educación Infantil 3-6 (12\%), Secundaria (11\%), Infantil y Primaria (8\%), Bachillerato (5\%) e Infantil 0-3 (3\%). Los profesores cuentan en su mayoria, según declaran, con una formación inicial en IE $(80 \%)$ y solo $25,5 \%$ de ellos tiene certificado en IE. Por último, 40\% del profesorado realiza programas de educación emocional en el aula, 30\% los realizan ellos/as mismos/as y solo un $8 \%$ se basan en un programa de IE prediseñado. El muestreo fue no probabilístico incidental.

\section{Instrumentos}

Se utilizaron tres instrumentos:

1) Trait Meta-Mood Scale (TMMS-24) para medir el nivel de regulación emocional del profesorado. Adaptación española de Fernández-Berrocal, Extremera y Ramos (2004 como se cita en Olivia et al., 2011). Evalúa la IE percibida a través de tres factores: (a) atención a los sentimientos, (b) claridad emocional y (c) reparación emocional. En este estudio sólo se considera la escala de reparación emocional, la cual hace referencia a la capacidad de regulación emocional. Esta escala comprende ocho items de respuesta tipo Likert desde 1 (nada de acuerdo) hasta 5 (totalmente de acuerdo). Por ejemplo, "Cuando estoy triste, pienso en todos los placeres de la vida". La fiabilidad (alpha de Cronbach) de la escala es de 0,86 (Oliva et al., 2011).

Para la evaluación de la escala se utiliza el baremo de la Tabla 1, distinguido por el género de los sujetos. Para ello se suman las puntuaciones de todos los items y se ubica a los sujetos en una de las tres categorias siguientes:

Tabla 1.

Baremos del TMMS-24

\begin{tabular}{lcl}
\hline Reparación emocional & Frecuencia & $\%$ \\
\hline Debe mejorar su reparación emocional & $\leq 23$ & $\leq 23$ \\
\hline Adecuada reparación emocional & 24 a 35 & 24 a 34 \\
\hline Excelente reparación emocional & $\geq 36$ & $\geq 35$ \\
\hline
\end{tabular}

Fuente: elaboración propia a partir de Oliva et al. (2011).

2) Cuestionario para analizar el nivel de regulación emocional del alumnado percibido por el profesorado. Para la construcción del 
cuestionario se utilizaron las clasificaciones de Mayer y Salovey (citado en Extremera y Fernández-Berrocal, 2004a, p. 73) y Bisquerra (2003) sobre el constructo. Con base en ello, se desarrollaron los ítems de la Tabla 2. El cuestionario mostró un indice de fiabilidad (alfa de Cronbach) de 0,853.

Cada ítem presenta tres respuestas en función de su adquisición y autonomia:

- (a) Sí, sin apoyo externo: la aptitud señalada se realiza de forma autónoma, sin pautas previas ni apoyo del profesorado o del grupo de iguales (compañeros/as).

- (b) Sí, con apoyo externo: la aptitud señalada se realiza con dependencia de pautas previas, apoyo del profesorado o del grupo de iguales (compañeros/as).

- (c) No: la aptitud señalada no está adquirida.

3) Cuestionario para evaluar la percepción docente sobre el impacto de la regulación emocional en el proceso de enseñanzaaprendizaje (Tabla 3).

El cuestionario se califica mediante una escala tipo Likert con cinco opciones de respuesta: de 1 (nada de acuerdo) a 5 (totalmente de acuerdo). 
Tabla 2 .

Cuestionario del nivel de regulación emocional del alumnado percibido por el profesorado

\begin{tabular}{|c|c|c|}
\hline DIMENSIÓN & FACTOR & PREGUNTAS \\
\hline \multirow[t]{2}{*}{$\begin{array}{l}\text { (a) Habilidad para } \\
\text { regular las } \\
\text { emociones propias } \\
\text { y ajenas de manera } \\
\text { objetiva }\end{array}$} & $\begin{array}{c}\text { Regulación emocional } \\
\text { personal }\end{array}$ & $\begin{array}{l}\text { Los alumnos: } \\
\text { ¿Son capaces de regular sus } \\
\text { emociones (utilizan técnicas y } \\
\text { estrategias para manejar de forma } \\
\text { adecuada sus emociones)? }\end{array}$ \\
\hline & $\begin{array}{l}\text { Regulación emocional } \\
\text { interpersonal }\end{array}$ & $\begin{array}{l}\text { ¿Son capaces de regular las emociones } \\
\text { de los demás (utilizan técnicas y } \\
\text { estrategias para manejar de forma } \\
\text { adecuada las emociones de los } \\
\text { demás)? }\end{array}$ \\
\hline \multirow{2}{*}{$\begin{array}{l}\text { (a) Habilidad para } \\
\text { vigilar las } \\
\text { emociones propias } \\
\text { y ajenas y } \\
\text { reconocer su } \\
\text { influencia en las } \\
\text { mismas }\end{array}$} & $\begin{array}{c}\text { Consciencia sobre el } \\
\text { impacto emocional en sí } \\
\text { mismos } \\
\end{array}$ & $\begin{array}{l}\text { ¿Conocen el impacto que les generan } \\
\text { sus emociones (a nivel cognitivo, } \\
\text { conductual, social...)? }\end{array}$ \\
\hline & $\begin{array}{c}\text { Consciencia sobre el } \\
\text { impacto emocional en los } \\
\text { demás }\end{array}$ & $\begin{array}{l}\text { ¿Reconocen el impacto que generan } \\
\text { sus emociones en los demás? }\end{array}$ \\
\hline \multirow{2}{*}{$\begin{array}{l}\text { (a) Habilidad para } \\
\text { reflexionar y } \\
\text { determinar la } \\
\text { utilidad de la } \\
\text { información de las } \\
\text { emociones }\end{array}$} & $\begin{array}{c}\text { Capacidad de reflexión, } \\
\text { análisis y comprensión } \\
\text { emocional }\end{array}$ & $\begin{array}{l}\text { ¿Saben reflexionar sobre sus } \\
\text { emociones (pensar, analizar y } \\
\text { comprender sus emociones)? }\end{array}$ \\
\hline & $\begin{array}{l}\text { Reconocimiento de la } \\
\text { información emocional }\end{array}$ & $\begin{array}{l}\text { ¿Saben reconocer la información que } \\
\text { les ofrecen sus emociones (por } \\
\text { ejemplo: "estoy enfadado y eso } \\
\text { significa que esta situación me resulta } \\
\text { incómoda e injusta...")? }\end{array}$ \\
\hline \multirow{2}{*}{$\begin{array}{l}\text { (a) Habilidad de } \\
\text { apertura alos } \\
\text { sentimientos } \\
\text { positivos y } \\
\text { negativos }\end{array}$} & $\begin{array}{c}\text { Aceptación de emociones } \\
\text { positivas } \\
\end{array}$ & $\begin{array}{l}\text { ¿Aceptan las emociones positivas (por } \\
\text { ejemplo: alegría, amor,....)? }\end{array}$ \\
\hline & $\begin{array}{c}\text { Aceptación de emociones } \\
\text { negativas }\end{array}$ & $\begin{array}{l}\text { ¿Aceptan las emociones negativas (por } \\
\text { ejemplo: ira, miedo, tristeza...)? }\end{array}$ \\
\hline \multirow{2}{*}{$\begin{array}{l}\text { (b)Tomar conciencia } \\
\text { de la interacción } \\
\text { entre emoción, } \\
\text { cognición y } \\
\text { comportamiento: } \\
\text { define la cognición } \\
\text { como base para la } \\
\text { regulación } \\
\text { emocional y } \\
\text { conductual. }\end{array}$} & $\begin{array}{c}\text { Consciencia sobre la } \\
\text { influencia del pensamiento } \\
\text { en el estado emocional }\end{array}$ & $\begin{array}{l}\text { ¿Conocen la influencia de los } \\
\text { pensamientos sobre las emociones } \\
\text { (saben que si modifican su } \\
\text { pensamiento son capaces de cambiar } \\
\text { su emoción)? }\end{array}$ \\
\hline & $\begin{array}{c}\text { Consciencia sobre la } \\
\text { influencia de la conducta en } \\
\text { el estado emocional }\end{array}$ & $\begin{array}{l}\text { ¿Conocen la influencia de sus } \\
\text { conductas sobre las emociones (saben } \\
\text { que pueden utilizar su cuerpo para } \\
\text { gestionar sus emociones)? }\end{array}$ \\
\hline \multirow{2}{*}{$\begin{array}{l}\text { (b)Capacidad para la } \\
\text { regulación } \\
\text { emocional: afirma } \\
\text { la necesidad de } \\
\text { autocontrol del } \\
\text { impulso y la } \\
\text { tolerancia a la } \\
\text { frustración para } \\
\text { evitar emociones } \\
\text { destructivas. }\end{array}$} & $\begin{array}{c}\text { Control de impulsos } \\
\text { emocionales }\end{array}$ & $\begin{array}{l}\text { ¿Controlan adecuadamente sus } \\
\text { impulsos con estrategias adecuadas? }\end{array}$ \\
\hline & Tolerancia a la frustración & $\begin{array}{l}\text { ¿Toleran adecuadamente la frustración } \\
\text { (ante el fracaso evalúan sus errores y } \\
\text { cambian sus estrategias para afrontar } \\
\text { eficazmente la situación)? }\end{array}$ \\
\hline
\end{tabular}

Fuente: elaboración propia a partir de (a) Mayer y Salovey (Extremera y Fernández- Berrocal, 2004, p. 73) y (b) Bisquerra (2003, p.23-24). 
Tabla 3.

Cuestionario para evaluar la percepción docente sobre el impacto de la regulación emocional en el proceso de enseñanza-aprendizaje

\begin{tabular}{|c|c|c|}
\hline DIMENSIÓN & FACTOR & PREGUNTAS \\
\hline \multirow{2}{*}{$\begin{array}{l}\text { Percepción } \\
\text { general sobre } \\
\text { la educación } \\
\text { en regulación } \\
\text { emocional }\end{array}$} & $\begin{array}{c}\text { Importancia dada a la } \\
\text { educación en regulación } \\
\text { emocional. }\end{array}$ & $\begin{array}{l}\text { Considero imprescindible la educación } \\
\text { en regulación emocional de mis } \\
\text { alumnos/as }\end{array}$ \\
\hline & $\begin{array}{c}\text { Recursos empleados para la } \\
\text { educación en regulación } \\
\text { emocional. }\end{array}$ & $\begin{array}{l}\text { Dedico los recursos necesarios para } \\
\text { educar en regulación emocional } \\
\text { (tiempo, material, espacio,...). }\end{array}$ \\
\hline \multirow{2}{*}{$\begin{array}{l}\text { Capacidad de } \\
\text { reconocimien } \\
\text { to emocional } \\
\text { del alumnado }\end{array}$} & $\begin{array}{c}\text { Facilidad de atención } \\
\text { emocional. }\end{array}$ & $\begin{array}{l}\text { Reconozco con facilidad las } \\
\text { emociones de mis alumnos/as. }\end{array}$ \\
\hline & $\begin{array}{l}\text { Regulación emocional del } \\
\text { alumnado percibida como } \\
\text { insuficiente. }\end{array}$ & $\begin{array}{l}\text { Considero insuficiente el nivel de } \\
\text { regulación emocional de mis } \\
\text { alumnos/as. }\end{array}$ \\
\hline \multirow[t]{3}{*}{$\begin{array}{l}\text { Motivación } \\
\text { docente }\end{array}$} & \multirow[t]{3}{*}{$\begin{array}{l}\text { Impacto de la escasa } \\
\text { regulación emocional del } \\
\text { alumnado en la } \\
\text { motivación docente. }\end{array}$} & $\begin{array}{l}\text { La escasa regulación emocional de } \\
\text { mis alumnos/as implica un reto que } \\
\text { me motiva a mejorar como } \\
\text { profesional. }\end{array}$ \\
\hline & & $\begin{array}{l}\text { La escasa regulación emocional de } \\
\text { mis alumnos/as me genera } \\
\text { indiferencia. }\end{array}$ \\
\hline & & $\begin{array}{l}\text { La escasa regulación emocional de } \\
\text { mis alumnos/as disminuye mi } \\
\text { motivación como docente. }\end{array}$ \\
\hline \multirow[t]{3}{*}{$\begin{array}{l}\text { Autoeficacia } \\
\text { docente }\end{array}$} & \multirow{3}{*}{$\begin{array}{l}\text { Incidencia de la escasa } \\
\text { regulación emocional del } \\
\text { alumnado en la autoeficacia } \\
\text { docente. }\end{array}$} & $\begin{array}{l}\text { La escasa regulación emocional de mis } \\
\text { alumnos/as aumenta mi eficacia como } \\
\text { docente. }\end{array}$ \\
\hline & & $\begin{array}{l}\text { La escasa regulación emocional de mis } \\
\text { alumnos/as no afecta a mi eficacia } \\
\text { como docente. }\end{array}$ \\
\hline & & $\begin{array}{l}\text { La escasa regulación emocional de mis } \\
\text { alumnos/as disminuye mi eficacia } \\
\text { como docente. }\end{array}$ \\
\hline $\begin{array}{l}\text { Emociones } \\
\text { en los } \\
\text { docentes }\end{array}$ & $\begin{array}{c}\text { Impacto de la escasa } \\
\text { regulación emocional del } \\
\text { alumnado en las } \\
\text { emociones del docente }\end{array}$ & $\begin{array}{l}\text { La escasa regulación emocional de } \\
\text { mis alumnos/as me genera } \\
\text { emociones negativas (ira, tristeza, } \\
\text { miedo,...). }\end{array}$ \\
\hline $\begin{array}{l}\text { Proceso de } \\
\text { enseñanza- } \\
\text { aprendizaje }\end{array}$ & $\begin{array}{l}\text { Impacto de la escasa } \\
\text { regulación emocional del } \\
\text { alumnado en el proceso de } \\
\text { E-A }\end{array}$ & $\begin{array}{l}\text { La escasa regulación emocional de mis } \\
\text { alumnos/as afecta el proceso de } \\
\text { enseñanza-aprendizaje (causa } \\
\text { disminución del ritmo, cambio de } \\
\text { contenidos, objetivos, evaluación,....). }\end{array}$ \\
\hline
\end{tabular}

Fuente: elaboración propia. 


\section{Procedimiento}

El cuestionario se aplicó a los profesores a través de la herramienta Formularios de Google, siendo completamente anónimo. Siguiendo las recomendaciones de Cerón (2006), se realizó un análisis previo del cuestionario mediante su puesta en común con cuatro profesionales de los distintos niveles académicos (Infantil, Primaria, SecundariaBachillerato y Universidad), tras el cual se adaptó el lenguaje disminuyendo su nivel técnico.

\section{Análisis de datos}

Estudio con diseño no experimental, transversal, descriptivo, correlacional. Todos los análisis estadísticos se realizaron a través del programa SPSS.

\section{Resultados}

\section{Nivel de regulación emocional del profesorado}

Respecto a las puntuaciones docentes en la escala de reparación emocional (regulación emocional) del TMMS-24, se encontró un mayor porcentaje $(76 \%)$ de profesores con adecuada regulación emocional, con $15 \%$ de ellos con una excelente regulación emocional y $9 \%$ que deben mejorarla. La puntuación media fue de 30,28 (DT=4,77).

Nivel de regulación emocional del alumnado percibido por el profesorado

A continuación, se muestran los resultados agrupados en cuatro factores principales.

- Capacidad de regulación emocional en uno mismo y en los demás. Un 68\% del profesorado afirma que sus alumnos pueden regular sus propias emociones a través de estrategias con apoyo externo, $7 \%$ consideran que sin apoyo y $25 \%$ niega que tengan esta habilidad. De manera similar, 53\% del profesorado percibe que sus alumnos pueden regular sus emociones a través de técnicas adecuadas con apoyo externo, $2,5 \%$ percibe que sin apoyo y $44,5 \%$ niega esta habilidad en el alumnado. Además, el 58,8\% del profesorado afirma que sus alumnos pueden controlar adecuadamente sus impulsos con apoyo externo, el $3 \%$ percibe que sin apoyo y el $38,2 \%$ niega esta capacidad en el alumnado. Asimismo, el 43,5\% del profesorado afirma que sus alumnos pueden tolerar la 
frustración con apoyo externo, el 3,5\% consideran que sin apoyo y el $53 \%$ no percibe esta habilidad en sus alumnos. Por su parte, el $56 \%$ del profesorado afirma que sus alumnos son capaces de regular las emociones de los demás con un apoyo externo, el $12 \%$ piensa que sin apoyo y el $32 \%$ niega dicha habilidad en su alumnado.

- Conciencia y tolerancia del impacto emocional en sí mismo/a y en los demás. Un 50,5 \% del profesorado afirma que sus alumnos son conscientes del impacto que les generan sus emociones con apoyo externo, el $9 \%$ considera que sin apoyo y el 40,5\% niega dicha habilidad en su alumnado. Por su parte, un $56,5 \%$ del profesorado afirma que sus alumnos pueden reconocer el impacto de sus emociones en los demás con apoyo externo, el $11,5 \%$ afirma que no necesitan ese apoyo y un $32 \%$ niega dicha habilidad en su alumnado. Por otro lado, el $44,5 \%$ del profesorado piensa que los alumnos toman consciencia de la influencia de los pensamientos sobre las emociones con apoyo externo, el $4 \%$ cree que sin apoyo y el $51,5 \%$ niega que sus alumnos lo hagan. Así también, el $42,5 \%$ del profesorado sostiene que sus alumnos toman consciencia sobre la influencia de la conducta en el estado emocional con apoyo externo, un $7 \%$ afirma que sin apoyo y el $50,5 \%$ niega que sus alumnos lo hagan.

- Reconocimiento y uso de la información emocional para el bienestar personal. El 69\% del profesorado afirma que su alumnado puede reflexionar sobre sus emociones con apoyo externo, el $8,5 \%$ piensa que sin apoyo y el $22,5 \%$ niega que su alumnado tenga esta habilidad. Asimismo, el 57\% del profesorado afirma que los alumnos pueden reconocer la información que les ofrecen las emociones con apoyo externo, el $19 \%$ considera que sin apoyo y el $23 \%$ niega esta habilidad en el alumnado.

- Selección y uso de las emociones en beneficio personal. La mayoría del profesorado percibe que sus alumnos pueden aceptar las emociones positivas con autonomía $(77,5 \%)$, el $20,5 \%$ considera que requieren de apoyo externo para su despliegue y el $2 \%$ niega dicha habilidad en su alumnado. De igual forma, más de la mitad del profesorado $(51,5 \%)$ considera que los alumnos pueden aceptar las emociones negativas con apoyo externo, el $18 \%$ piensa que sin apoyo y el $30,5 \%$ niega dicha habilidad en los alumnos. Por su parte, el $43 \%$ del profesorado percibe que sus alumnos pueden generar emociones positivas con apoyo externo, el $12 \%$ piensa que sin 
apoyo y el $45 \%$ no percibe dicha habilidad en el alumnado. Así también, el $62,5 \%$ del profesorado percibe que sus alumnos pueden beneficiarse de su expresión emocional con apoyo externo, el $27,5 \%$ afirma que sin apoyo y el $10 \%$ niega esta habilidad en sus alumnos.

\section{Percepción docente respecto al impacto de la regulación emocional en el proceso de enseñanza-aprendizaje}

A continuación, se muestran los resultados en las distintas dimensiones.

- Percepción sobre la educación en regulación emocional. La mayoría del profesorado $(97,5 \%)$ considera imprescindible la educación en regulación emocional; con puntajes entre totalmente de acuerdo (54\%), muy de acuerdo (32\%) y bastante de acuerdo $(11,5 \%)$, frente a quienes están algo de acuerdo $(0,5 \%)$ y quienes no lo están $(1,5 \%)$. Por su parte, la mayoría del profesorado $(83,5 \%)$ está de acuerdo en que dedica los recursos necesarios para educar en regulación emocional; con puntuaciones entre totalmente de acuerdo $(11,5 \%)$, bastante de acuerdo $(38,5 \%)$, muy de acuerdo $(33,5 \%)$, frente a quienes están algo de acuerdo (14\%) y quienes no lo están (3\%).

- Capacidad de reconocimiento emocional del alumnado. La mayoría del profesorado (93\%) está de acuerdo en que reconoce con facilidad las emociones del alumnado; con puntajes entre totalmente de acuerdo (13,5\%), muy de acuerdo (53\%) y bastante de acuerdo (26,5\%), frente a quienes dudan de dicha habilidad (7\%). Por otro lado, el 89,5\% de los docentes considera insuficiente el nivel de regulación emocional del alumnado, frente a un $10,5 \%$ que niega dicha afirmación.

Tras estos resultados se evalúa el impacto de la regulación emocional en el aula:

Motivación docente. La mayoría del profesorado (92\%) afirma estar de acuerdo con que el bajo nivel de regulación emocional del alumnado le supone un reto y por tanto aumenta su motivación docente; con puntajes entre totalmente de acuerdo (31\%), muy de acuerdo (44\%), y bastante de acuerdo (17\%); frente a los docentes que dicen estar algo de acuerdo (5\%) y quienes niegan dicha afirmación $(2,5 \%)$. Contrariamente, el $76,5 \%$ los docentes niegan que la escasa regulación emocional de los alumnos les genera indiferencia y el 14\% que está algo 
de acuerdo con la afirmación, frente a quienes afirman estar totalmente de acuerdo (1,5\%), muy de acuerdo (1,5\%) bastante de acuerdo (7\%) con esta afirmación. Por su parte, más de la mitad del profesorado (55\%) niega que el bajo nivel de regulación emocional del alumnado disminuya su motivación docente; mediante la selección en algo de acuerdo $(29 \%)$ y nada de acuerdo (26\%), frente al $27 \%$ que está bastante de acuerdo, el $14 \%$ muy de acuerdo y el $4 \%$ totalmente de acuerdo.

- $\quad$ Autoeficacia docente. Más de la mitad del profesorado (50,5\%) está de acuerdo con que la escasa regulación emocional de los alumnos aumenta su eficacia como docentes; con puntuaciones entre totalmente de acuerdo $(32,5 \%)$ y muy de acuerdo (18\%), frente a quienes están algo de acuerdo $(24,5 \%)$. En cuanto a si la escasa regulación emocional de los alumnos disminuye la eficacia docente el 18,5\% expresa estar en nada de acuerdo frente al $6,5 \%$ que está totalmente de acuerdo.

- Emociones en los docentes. Respecto al impacto de la escasa regulación emocional del alumnado en las emociones negativas del profesorado, el 55,5\% manifiesta estar nada de acuerdo y algo de acuerdo, frente a un $26,5 \%$ que dice estar bastante de acuerdo, el $13,5 \%$ muy de acuerdo y el $4,5 \%$ totalmente de acuerdo.

- Proceso de enseñanza-aprendizaje. El 88\% del profesorado califica desde bastante de acuerdo hasta totalmente de acuerdo el impacto de la regulación emocional sobre el proceso de enseñanza-aprendizaje, frente al 4\% que no está de acuerdo y el $8 \%$ algo de acuerdo.

\section{Relación entre la regulación emocional del profesorado y la incidencia de la regulación emocional en el proceso de enseñanza-aprendizaje.}

Como se observa en la Tabla 4, se encontró una correlación significativa entre el nivel de regulación emocional docente y la importancia dada a la educación en regulación emocional $(r=0,180$; $\mathrm{p}=0,011$ ), en los recursos dados a la educación en regulación emocional $(\mathrm{r}=0,147 ; \mathrm{p}=0,037)$, el reconocimiento emocional del profesorado $(\mathrm{r}=0,238 ; 0,001)$, la consideración insuficiente de la regulación emocional del alumnado $(\mathrm{r}=0,156 ; \mathrm{p}=0,028)$ y la motivación docente ante el bajo nivel de regulación emocional del alumnado $(\mathrm{r}=0,166$; $\mathrm{p}=0,019$ ). 
Tabla 4.

Relación entre la regulación emocional del profesorado y las variables de impacto de la regulación emocional en el proceso de enseñanzaaprendizaje $(n=200)$

\begin{tabular}{llllllllll}
\hline & $\mathbf{V}$ & $\mathbf{V 2}$ & $\mathbf{V 3}$ & $\mathbf{V 4}$ & $\mathbf{V 5}$ & $\mathbf{V 6}$ & $\mathbf{V 7}$ & $\mathbf{V 8}$ & $\mathbf{V 9}$ \\
& $\mathbf{1}$ & & & & & & & & \\
\hline & & & & & & & & & \\
Correlación &, 180 &, 147 &, 238 &, 156 &, 09 &, 07 &, 04 & - &, 166 \\
de Pearson & $*$ & $*$ & $*$ & $*$ & 1 & 5 & 1 &, 062 & $*$ \\
Sig. (bilateral) &, 01 &, 037 &, 001 &, 028 &, 20 &, 29 &, 56 &, 382 &, 01 \\
& 1 & & & & 1 & 0 & 4 & & 9 \\
\hline
\end{tabular}

Fuente: elaboración propia mediante la herramienta SPSS.

Nota. (V1) Importancia dada a la educación en regulación emocional; (V2) Recursos dados a la educación en regulación emocional; (V3) Reconocimiento emocional del profesorado; (V4) Consideración insuficiente de la regulación emocional; (V5) Impacto de la regulación emocional en el ritmo del proceso de enseñanza- aprendizaje; (V6) Impacto de la regulación emocional en la desmotivación docente; (V7) Impacto de la regulación emocional en la eficacia docente; (V8) Impacto de la regulación emocional en la motivación docente; (V9) Impacto de la regulación emocional indiferente.

\section{Discusión y conclusiones}

Con arreglo del objetivo principal del presente trabajo, analizar la incidencia de la regulación emocional en el aula, percibida por el profesorado de distintos niveles educativos en España, a continuación, se discuten los principales resultados obtenidos.

En lo que respecta a las puntuaciones docentes en regulación emocional, en su mayoría (91\%) los profesores cuentan con adecuada o excelente regulación emocional. Nuestros hallazgos son muy alentadores, ya que como se dijo en el artículo, existen múltiples beneficios de contar con docentes con óptimos niveles de IE, y con ello de regulación emocional; en general constituyen un elemento que salvaguarda el equilibrio y bienestar psicológico, al tiempo que incide en el desempeño docente y en las relaciones positivas con los distintos agentes educativos (Echevarría y López-Zafra, 2011; Martínez-Otero et al., 2005, 2006).

Por otro lado, la mayoría del profesorado considera que el nivel de 
regulación emocional del alumnado es insuficiente. Aunque, al parecer, esta percepción les supone un reto y aumenta su motivación y autoeficacia durante el proceso de enseñanza aprendizaje. De manera específica, más de la mitad del profesorado considera que los alumnos requieren ayuda para reconocer, reflexionar y analizar sus emociones negativas, así como para tener conciencia del impacto de dichas emociones en sí mismos y en otras personas. Además, consideran que los alumnos necesitan apoyo en el uso de estrategias y técnicas adecuadas para controlar sus impulsos emocionales, para beneficiarse de su expresión emocional y para la regulación interpersonal. Por otro lado, menos de la mitad del profesorado afirma que los alumnos requieren apoyo para generar emociones positivas y para ser conscientes de dichas emociones.

Téngase presente que los efectos positivos de la regulación emocional van más allá de las relaciones interpersonales, ya que se extienden a otras situaciones potencialmente estresantes (preparación de exámenes y proyectos, uso de tecnologías...), así como el afrontamiento de situaciones de riesgo (consumo de drogas, alcohol, ...), que demanda una mayor regulación intrapersonal -cognitiva, emocional y conductual-. Es preciso, por tanto, como bien señalan Martínez-Otero et al. (2005), que estas habilidades se ejerciten en todos los alumnos, no sólo en aquellos que presentan un comportamiento deficitario, y, de ser posible, desde la infancia temprana.

En este sentido, se observó una tendencia por parte del profesorado a entender como imprescindible la educación en regulación emocional y a este respecto, la mayoría de ellos consideran que reconocen las emociones del alumnado y que dedican los recursos necesarios para educar en regulación emocional. Coincidimos con Martínez-Otero et al. (2005, p. 21), en que "el profesor debe ser un profesional íntegro que promueva el desarrollo racional y socio-afectivo de los alumnos", por lo que el desarrollo de la vertiente afectiva, reflejo de la importancia que el profesorado atribuye a dicho ámbito, puede ser muy beneficiosa en contextos escolares muy diversos en los que es preciso el despliegue de la personalidad de los educandos de manera satisfactoria y de un convivencia armónica en al contexto escolar.

Finalmente, partir del análisis de correlación, se puede afirmar que a mayor puntuación en regulación emocional del profesorado más importancia se concede a la educación en regulación emocional, mayor reconocimiento de las emociones de su alumnado, además de observar niveles de regulación emocional del alumnado como insuficientes y tomar dicho nivel como un reto motivador en su labor docente. Estos resultados corroboran que la IE no es estática, lo que ha de animar a revisar los distintos proyectos y programas para seleccionar el más 
oportuno, de acuerdo con las necesidades del profesorado y a las realidades que enfrentan en los distintos contextos y niveles educativos.

Los resultados anteriores y los de otros estudios previos (AguayoMuela y Aguilar-Luzón, 2017; Martínez-Otero et al., 2006; Palomero, 2009; Pena et al., 2012; Rey y Extremera, 2011) plantean la necesidad de atención a la educación en regulación emocional en el aula, debido a su impacto en el bienestar y satisfacción del profesorado, así como en la eficacia y calidad de los procesos de enseñanza-aprendizaje, lo que a su vez puede contribuir a la mejora de la calidad del sistema educativo español.

La educación inclusiva y personalizada que se defiende pedagógicamente en la actualidad exige al ámbito científico un análisis de las propuestas llevadas a cabo en educación emocional para su posterior selección según las necesidades encontradas en los distintos contextos escolares. Es nuestra tarea abordar dicha necesidad y, por tanto, como profesionales de la educación, no debemos escatimar los esfuerzos. Los hallazgos nos animan a enfatizar la importancia de la regulación emocional, que, como parte de la IE, constituye un soporte para comprender mejor ciertas variables emocionales y su incidencia en el desarrollo personal docente y del alumnado (Cejudo y López-Delgado, 2017; Márquez-Cervantes y Gaeta-González, 2017); que favorezcan un mayor autoconocimiento y apertura a los demás hacia una canalización de la afectividad que garantice procesos de enseñanza-aprendizaje de calidad.

Por otro lado, cabe señalar algunas limitaciones de la presente investigación, como el tamaño de la muestra, así como el carácter subjetivo del constructo, lo que se traduce en que los instrumentos seleccionados evalúen la percepción de los docentes sobre el objeto de estudio. Por lo que es necesario contrastar con otro tipo de valoraciones, como por ejemplo observaciones en el aula. Sería deseable, además, la realización de un estudio cuasiexperimental que permita conocer el impacto de la educación en regulación emocional tanto del profesorado como del alumnado, con el propósito de mejorar dicho impacto en los procesos de enseñanza-aprendizaje y en el desarrollo integral. Asimismo, sería positivo conocer el impacto de la regulación emocional entre iguales, debido a su interés metodológico y psicopedagógico, pudiendo ser un marco de referencia para futuros proyectos de intervención. Otro de los ámbitos a investigar es el impacto familiar, pues resulta necesario conocer la proyección que presenta el ámbito de la regulación emocional en las familias, lo que abre un prometedor campo de investigación y de actuación. 


\section{Referencias}

Adame, M. T., De La Iglesia, B., Gotzens, C., Rodríguez, R. I., \& Sureda, I. (2011). Análisis de las estrategias socioemocionales utilizadas por los y las docentes en el aula: estudio de casos. Revista Electrónica Interuniversitaria de Formación del Profesorado, 14(3), 77-86.

Aguayo-Muela, Á. D. C., \& Aguilar-Luzón, M. D. C. (2017). Principales resultados de investigación sobre Inteligencia Emocional en Docentes Españoles. ReiDoCrea, 6, 170-193.

Alonso, L. M., \& Escorcia, I. (2003). El ser humano como una totalidad. Salud Uninorte, 17, 3-8.

Andrés, M. L., Castañeiras, C. E., \& Richaud, M. C. (2014). Contribución de las estrategias cognitivas de regulación emocional en ansiedad, depresión y bienestar en niños de 10 años. Resultados preliminares. PSIENCIA. Revista Latinoamericana de Ciencia Psicológica, 6(2), 81-89.

Autismo Madrid (2014) Programa Ulises: Aprendizaje y desarrollo del autocontrol emocional. Recuperado de http://autismomadrid.es/educacion-2/programa- ulisesaprendizaje-y-desarrollo-del-autocontrol-emocional/

Berrocal, P. F. (2008). La Educación Emocional y Social en España. España: Fundación Botín. Recuperado de: http://www.fundacionbotin.org/89dguuytdfr276ed_uploads/ED UCACION/AN ALISIS\%20INTERNACIONAL/2008/Espaa2008.pdf

Berrocal, P. F., \& Extremera, N. (2005). La Inteligencia Emocional y la educación de las emociones desde el Modelo de Mayer y Salovey. Revista Electrónica Interuniversitaria de Formación del Profesorado, 19(3), 63-93.

Bisquerra, R. (2003). Educación emocional y competencias básicas para la vida. Revista de Investigación Educativa, 21(1), 7-43.

Bisquerra, R. (2009). Psicopedagogía de las emociones. Madrid: Sintesis.

Cejudo, J., López-Delgado, M. L., Rubio, M. J., \& Latorre, J. M. (2015). La formación en educación emocional de los docentes: una visión de los futuros maestros. Revista Española de Orientación y 
Psicopedagogía, 26(3), 45-62.

Cejudo, J., \& López-Delgado, M. (2017). Importancia de la inteligencia emocional en la práctica docente: un estudio con maestros. Psicología Educativa, 23(1), 29-36.

Cerón, M. C. (2006). Metodologías de investigación social. Santiago de Chile: LOM.

Delors, J. (1996). Los cuatro pilares de la educación. La Educación Encierra un Tesoro. Recuperado de http:/ /xa.yimg.com/kq/groups/22882378/877123863/name/L os+cuatro+pilar es+de+la+educaci\%C3\%B3n.pdf

Echevarría, A., \& López-Zafra, E. (2011). Pigmalión, ¿`sigue vivo? Inteligencia emocional y la percepción del profesorado de alumnos de ESO. Boletín de Psicología, 2, 7-22.

Extremera, N., \& Fernández-Berrocal, P. (2004a). La importancia de desarrollar la inteligencia emocional en el profesorado. Revista Iberoamericana de Educación, 33(8), 1-9.

Extremera, N., \& Fernández-Berrocal, P. (2004b). El papel de la inteligencia emocional en el alumnado: evidencias empíricas. Revista Electrónica de Investigación Educativa, 6(2), 1-17.

Fundación Botín (2017). Educación Responsable. Recuperado de http: / /www.fundacionbotin.org/educacioncontenidos/educacion- responsable.html

Fundación de Ayuda contra la Drogadicción (2011). Construye tu Mundo. Madrid: FAD. Recuperado de: http://www.fad.es/sites/default/files/CTM.pdf

Gardner, H. (2011). Inteligencias múltiples, la teoría en la práctica. España: Paidós.

Goleman D. (2014). Inteligencia emocional. España: Kairós.

GROP (Grupo de Investigación en Orientación Psicopedagógica) (s.f.) Presentación. Recuperado de: http://www.ub.edu/grop/es/

Ley Orgánica 8/2013, de 9 de diciembre, para la Mejora de la Calidad Educativa

(LOMCE).

Recuperado de: 
https://www.boe.es/diario_boe/txt.php?id=BOE-A-2013- 12886

Márquez-Cervantes, M. C., \& Gaeta-González, M. L. (2017). Desarrollo de competencias emocionales en pre-adolescentes: El papel de padres y docentes. Revista Electrónica Interuniversitaria de Formación del Profesorado, 20(2), 221-235.

Martínez-González, A. E., Piqueras, J. A., \& Ramos, V. (2010). Inteligencia emocional en la salud fisica y mental. Electronic Journal of Research in Educational Psychology, $\quad 8(21)$. Recuperado de http://www.redalyc.org/html/2931/293122002020/

Martínez-Otero, V. (2007). La inteligencia afectiva. Teoría, práctica y programa. Madrid: CCS.

Martínez-Otero, V., \& Velado-Guillén, L. A. (2002). La inteligencia afectiva en la escuela. Un estudio de una muestra de alumnos de psicopedagogía. Revista Educación y Futuro, 2, 1-12.

Martínez-Otero, V., García-Domingo, B., \& Velado-Guillén, L. A. (2005). Evaluación de la Inteligencia Afectiva en una muestra de alumnos de carreras de Educación. Psicopatología, 25(2), 17-40.

Martínez-Otero, V., García-Domingo, B., \& Velado-Guillén, L. A. (2006). Estrés, ansiedad e inteligencia afectiva en una muestra de futuros profesionales de la educación. Psicopatología, 26(1 y 2), 79-92.

Millán, A., García-Álvarez, D., \& D’Aubeterre, M. (2014). Efecto de la inteligencia emocional y flujo en el trabajo sobre estresores y bienestar psicológico: análisis de ruta en docentes. Revista Colombiana de Psicología, 23(1), 207-228.

Miñaca, M. I., Hervás, M., \& Laprida, I. (2013). Análisis de programas relacionados con la Educación Emocional desde el modelo propuesto por Salovey \& Mayer. Revista de Educación Social, 17. Recuperado http://rabida.uhu.es/dspace/bitstream/handle/10272/10243/ Analisis_de_pro gramas.pdf?sequence $=2$

Navas, J. M. M., \& Bozal, R. G. (2012). La regulación de las emociones. Una vía a la adaptación personal y social. Madrid: Ediciones Pirámide 
Oliva, A., Antolín, L., Pertegal, M. A., Ríos, M., Parra, A., Hernando, A., \& Reina, M. C. (2011). Instrumentos para la evaluación del desarrollo positivo adolescente y los activos que lo promueven. Sevilla: Departamento de Psicología Evolutiva y de la Educación. Universidad de Sevilla. Recuperado de https://imagenysalud14.files.wordpress.com/2014/12/instrume ntos- evaluacic3b3n-desarrollo-positivo-adolescente.pdf

Palomera, R., Márquez, P., \& Brackett, M. A. (2006). ¿Se perciben con inteligencia emocional los docentes?: posibles consecuencias sobre la calidad educativa. Revista de Educación, 341, 687-703.

Palomero, P. (2009). Desarrollo de la competencia social y emocional del profesorado: una aproximación desde la psicología humanista. Revista Electrónica Interuniversitaria de Formación del Profesorado, 12(2), 145-153.

Pena, M., Rey, L., \& Extremera, N. (2012). Bienestar personal y laboral en el profesorado de Infantil y Primaria: Diferencias en función de su inteligencia emocional y del género. Revista de Psicodidáctica, 17(2), 341-360.

Rey, L., \& Extremera, N. (2011). El apoyo social como un mediador de la inteligencia emocional percibida y la satisfacción vital en una muestra de profesorado. Revista de Psicología Social, 26(3), 401412.

Rey, R. A., Valero, A. P. B., Paniello, S. H., \& Monge, M. M. S. (2012). Programa Aulas Felices. Psicología Positiva aplicada a la Educación. Recuperado de http: / /www.juntadeandalucia.es/educacion/webportal/ishareservlet/content/536703bb-0748-4071-a0bd-31e6d384beff

Román, A. S., \& Calleja, L. S. (2012). Antiprograma de educación emocional. Sentir en primera persona. España: Wolters Kluwer España, S.A. Recuperado de http: / /www.juntadeandalucia.es/educacion/webportal/ishareservlet/content/7fe87c4f-9110-4299-b9e8-a52a8721beba

Segura, M., \& Arcas, M. (s.f.). Programa de competencia social Decide tú I. Primaria Primero y segundo ciclo. Recuperado de https://convivencia.files.wordpress.com/2011/10/decidetu_iseg ura172p.pdf 
Verdet, M. J. C. (2011) Cultivando emociones. Educación emocional de 3 a 8 años. Valencia: Generalitat Valenciana. Recuperado de http://www.lavirtu.com/eniusimg/enius4/2012/06/adjuntos_fic hero_695712_f 85eecff7d7e5afb.pdf 